\title{
Cellular Mechanisms Underlying Burst Firing in Substantia Nigra Dopamine Neurons
}

\author{
Sarah N. Blythe, ${ }^{1}$ David Wokosin, ${ }^{1}$ Jeremy F. Atherton, ${ }^{1}$ and Mark D. Bevan ${ }^{1,2}$ \\ ${ }^{1}$ Department of Physiology, Feinberg School of Medicine, Northwestern University, Chicago, Illinois 60611, and ${ }^{2}$ Department of Biomedical Science, \\ Western Bank, University of Sheffield, Sheffield, S10 2TN, United Kingdom
}

Burst firing of substantia nigra dopamine (SN DA) neurons is believed to represent an important teaching signal that instructs synaptic plasticity and associative learning. However, the mechanisms through which synaptic excitation overcomes the limiting effects of somatic $\mathrm{Ca}^{2+}$-dependent $\mathrm{K}^{+}$current to generate burst firing are controversial. Modeling studies suggest that synaptic excitation sufficiently amplifies oscillatory dendritic $\mathrm{Ca}^{2+}$ and $\mathrm{Na}^{+}$channel currents to lead to the initiation of high-frequency firing in SN DA neuron dendrites. To test this model, visually guided compartment-specific patch-clamp recording and ion channel manipulation were applied to rodent SN DA neurons in vitro.

As suggested previously, the axon of SN DA neurons was typically found to originate from a large-diameter dendrite that was proximal to the soma. However, in contrast to the predictions of the model, (1) somatic current injection generated firing that was similar in frequency and form to burst firing in vivo, (2) the efficacy of glutamatergic excitation was inversely related to the distance of excitation from the axon, (3) pharmacological blockade or genetic deletion of $\mathrm{Ca}^{2+}$ channels did not prevent high-frequency firing, (4) action potential bursts were invariably detected first at sites that were proximal to the axon, and (5) pharmacological blockade of $\mathrm{Na}^{+}$channels in the vicinity of the axon/soma but not dendritic excitation impaired burst firing. Together, these data suggest that SN DA neurons integrate their synaptic input in a more conventional manner than was hypothesized previously.

\section{Introduction}

In vivo substantia nigra dopamine (SN DA) neurons exhibit lowfrequency $(<4 \mathrm{~Hz})$ regular/irregular activity, punctuated by brief periods of high-frequency $(>10 \mathrm{~Hz}$ ) burst firing (Wilson et al., 1977; Guyenet and Aghajanian, 1978; Grace and Bunney, 1980; Hyland et al., 2002; Schultz, 2006). In awake animals, burst firing is associated with items of biological value or stimuli that predict their receipt (Schultz et al., 1997; Hyland et al., 2002). Burst firing generates a profound increase of DA in target areas, such as the striatum (Gonon, 1988), which in turn promotes synaptic plasticity (Centonze et al., 2001; Reynolds et al., 2001; Kreitzer and Malenka, 2007; Shen et al., 2008) and consolidates behavior (Schultz et al., 1997). The precisely timed nature of burst firing, its sensitivity to receptor antagonists, and its absence in deafferented preparations demonstrate that synaptic input is essential for its generation (Overton and Clark, 1997). Indeed, synaptic stimulation or dendritic application of glutamate in vitro generates in vivo-like burst firing (Morikawa et al., 2003; Blythe et al.,

Received June 18, 2009; revised 0ct. 16, 2009; accepted Nov. 2, 2009.

This work was supported by National Institutes of Health (NIH) Grants NSO20702, NS041280, and NS047085. S.N.B. was supported by NIH Grants AG-020418 and MH-067564 as a graduate student of the Northwestern University Interdepartmental Neuroscience program. We thank Jim Surmeier, Jim Tepper, and Charlie Wilson for helpfu discussions throughout the course of this study. We are particularly appreciative to Steve Kitai for his support during the initial phase of this project.

Correspondence should be addressed to Dr. Mark Bevan, Physiology M211, Feinberg School of Medicine, Northwestern University, 303 East Chicago Avenue, Chicago IL 60611-3008. E-mail: m-bevan@northwestern.edu. DOI:10.1523/JNEUROSCI.2961-09.2009

Copyright $\odot 2009$ Society for Neuroscience ～0270-6474/09/2915531-11\$15.00/0
2007). However, the mechanisms through which synaptic inputs generate burst firing are controversial.

Voltage-dependent $\mathrm{Na}^{+}\left(\mathrm{Na}_{\mathrm{v}}\right), \mathrm{Ca}^{2+}\left(\mathrm{Ca}_{\mathrm{v}}\right)$, and $\mathrm{K}^{+}\left(\mathrm{K}_{\mathrm{v}}\right)$ channels, mixed cation channels, and small-conductance $\mathrm{Ca}^{2+}$ dependent $\mathrm{K}^{+}$(SK) channels regulate the activity of SN DA neurons (Shepard and Bunney, 1988; Grace and Onn, 1989; Harris et al., 1989; Nedergaard et al., 1993; Mercuri et al., 1994; Liss et al., 2001; Neuhoff et al., 2002; Chan et al., 2007; Kim et al., 2007; Puopolo et al., 2007). $\mathrm{Na}_{\mathrm{v}}, \mathrm{Ca}_{\mathrm{v}}$, hyperpolarization-activated cyclic nucleotide-gated cation ( $\mathrm{HCN})$, and nonselective cation channels underlie depolarizing currents, whereas A-type $\mathrm{K}_{\mathrm{v}}$ and SK channels underlie hyperpolarizing currents. The large magnitude and long duration of currents generated by somatic SK channels are particularly thought to restrict activity (Kuznetsov et al., 2006). G-protein-coupled receptor-mediated reduction in SK channel current was therefore initially thought essential for burst firing. However, this form of modulation has not been identified (Morikawa et al., 2003), and the distinctive activity pattern that follows blockade of SK channels (Shepard and Bunney, 1988; Johnson and Wu, 2004; Kuznetsov et al., 2006) implies the existence of alternative mechanisms. Thus, the rapid clearance of intracellular $\mathrm{Ca}^{2+}$ from small-diameter dendrites (and thus smaller magnitude/shorter duration of dendritic SK current) was proposed to confer dendrites with the capability to oscillate at higher frequencies than the somatic compartment in which $\mathrm{Ca}^{2+}$ is cleared more slowly (Wilson and Callaway, 2000). Furthermore, NMDA receptor-mediated synaptic inputs were proposed to amplify dendritic $\mathrm{Ca}_{\mathrm{v}}$ and $\mathrm{Na}_{\mathrm{v}}$ channel currents such that action potentials initiate in dendrites and overcome the lim- 
iting effects of the soma (Kuznetsov et al., 2006). However, other studies suggest that action potentials are invariably initiated in the axonal compartment before propagating into the somatodendritic compartment (Häusser et al., 1995; Gentet and Williams, 2007). Thus, to further address the mechanisms that underlie burst firing in SN DA neurons, we used conventional microscopy-guided or two-photon laser scanning microscopy (2PLSM)-guided compartment-specific patch-clamp recording and ion channel manipulation during synaptic stimulation-evoked or exogenous glutamate-evoked activity.

\section{Materials and Methods}

Slice preparation. Procedures involving animals were performed in accordance with the policies of the National Institutes of Health and were approved by the Northwestern University Institutional Animal Care and Use Committee. Brain slices were prepared from Sprague Dawley rats [postnatal day 12 (P12) to P55] or where specified transgenic bacterial artificial chromosome (BAC) $\mathrm{D}_{2}$ enhanced green fluorescent protein (EGFP) Cacnald knock-out/wild-type (P22-P31) mice (Day et al., 2006). Animals were deeply anesthetized with ketamine/xylazine (87 and $13 \mathrm{mg} / \mathrm{kg}$, i.p., respectively) and then perfused via the ascending aorta with 10-30 ml of ice-cold modified artificial CSF (ACSF), which contained the following (in $\mathrm{mm}$ ): 230 sucrose, $26 \mathrm{NaHCO}_{3}, 2.5 \mathrm{KCl}, 1.25$ $\mathrm{NaH}_{2} \mathrm{PO}_{4}, 0.5 \mathrm{CaCl}_{2}, 10 \mathrm{MgSO}_{4}$, and 10 glucose (equilibrated with $95 \%$ $\mathrm{O}_{2}-5 \% \mathrm{CO}_{2}$ ). Each brain was rapidly removed, blocked along the midline, glued to the stage of a vibratome (model 3000; Vibratome), and immersed in modified ACSF at $\sim 0.5^{\circ} \mathrm{C}$. Coronal/sagittal slices containing the SN were cut at $250-300 \mu \mathrm{m}$ before being transferred to a holding chamber, which contained the following (in $\mathrm{mm}$ ): $126 \mathrm{NaCl}, 26$ $\mathrm{NaHCO}_{3}, 2.5 \mathrm{KCl}, 1.25 \mathrm{NaH}_{2} \mathrm{PO}_{4}, 2 \mathrm{CaCl}_{2}, 2 \mathrm{MgSO}_{4}$, and 10 glucose (equilibrated with $95 \% \mathrm{O}_{2}-5 \% \mathrm{CO}_{2}$ ).

Visualized recording. Individual slices were recorded in a chamber that was perfused at $2-4 \mathrm{ml} / \mathrm{min}$ with synthetic interstitial fluid, which contained the following (in mM): $126 \mathrm{NaCl}, 26 \mathrm{NaHCO}_{3}, 3 \mathrm{KCl}, 1.25 \mathrm{NaH}_{2} \mathrm{PO}_{4}, 1.6$ $\mathrm{CaCl}_{2}, 1.5 \mathrm{MgSO}_{4}$, and 10 glucose (equilibrated with $95 \% \mathrm{O}_{2}-5 \% \mathrm{CO}_{2}$, heated to $35-37^{\circ} \mathrm{C}$ ). Neurons were first selected for recording using Dodt contrast optics. For conventional microscopy, a fixed-stage upright microscope (Axioskop 2 FS plus; Zeiss) equipped with a $60 \times, 0.9$ numerical aperture objective (Olympus) and an infrared filter was used. For 2PLSM a fixedstage upright microscope (BX51WI; Olympus) equipped with a $60 \times, 0.9$ numerical aperture lens (Olympus) and an Ultima 2P system (Prairie Technologies) was used. A tunable laser (Verdi 5W Mira 900F; Coherent) was used as a light source for two-photon imaging. Neurons were imaged at 800 $\mathrm{nm}$ with $76 \mathrm{MHz}$ pulse repetition and $\sim 200 \mathrm{fs}$ pulse duration at the sample plane.

Electrophysiological recordings used borosilicate glass pipettes (Warner Instruments) with an impedance of 4-12 $\mathrm{M} \Omega$. Recordings were made in the tight-seal cell-attached, whole-cell or perforated configurations. For whole-cell and cell-attached recording, pipettes were filled with a solution containing the following (in $\mathrm{mm}$ ): $135 \mathrm{~K}-\mathrm{MeSO}_{4}, 3.8 \mathrm{NaCl}, 1$ $\mathrm{MgCl}_{2} \cdot 6 \mathrm{H}_{2} \mathrm{O}, 10$ HEPES, $0.1 \mathrm{Na}_{4}$-EGTA, $0.4 \mathrm{Na}_{3}$-GTP, and $2 \mathrm{Mg}$-ATP, $\mathrm{pH}$ 7.3. To visualize neurons under 2PLSM, $20 \mu \mathrm{M}$ Alexa Fluor 568 hydrazide sodium salt (Invitrogen) was added. To visualize neurons after recording, $0.5 \%$ biocytin was routinely added. For perforated patch recording, gramicidin D (Sigma) was added at a concentration of $20 \mu \mathrm{g} / \mathrm{ml}$ to gain electrical access.

Electrophysiological records were acquired using a computer running Clampex 9/10 software (Molecular Devices) connected to a Multiclamp 700B amplifier (Molecular Devices) via a Digidata 1322A digitizer (Molecular Devices). Data were low-pass filtered at $10-30 \mathrm{kHz}$ and sampled at $50-100 \mathrm{kHz}$. Electrode capacitance was compensated online. Wholecell and perforated patch-clamp recordings were corrected offline for liquid junction potentials of 9 and $4 \mathrm{mV}$, respectively (Baufreton et al., 2005).

Generation of burst firing in SN DA neurons. Burst firing was generated through local electrical stimulation (50-100 stimuli at 50-100 Hz; stimulus duration, $0.1 \mathrm{~ms}$; stimulus intensity, $100-600 \mu \mathrm{A}$ ) of glutamatergic afferents or pressure-pulse application $(25$ pulses at $50 \mathrm{~Hz}$; pulse duration, $10 \mathrm{~ms}$; pulse pressure, $0.1-0.2 \mathrm{bar}$ ) of $1 \mathrm{~mm}$ glutamate [dissolved in a solution containing the following (in $\mathrm{mM}$ ): $140 \mathrm{NaCl}, 23$ glucose, 15 HEPES, $2 \mathrm{KCl}, 2 \mathrm{MgCl}_{2}$, and $1 \mathrm{CaCl}_{2}, \mathrm{pH} 7.2$ (300 mOsm)]. $\mathrm{GABA}_{\mathrm{A}}$, $\mathrm{GABA}_{\mathrm{B}}, \mathrm{D}_{2}$, and type 1 metabotropic glutamate receptor antagonists were continuously bath applied to block inhibition and maximize glutamatergic excitation. Bipolar electrical stimulation (A360 stimulus isolator; World Precision Instruments) was applied via a matrix stimulating electrode (four rows of five tungsten electrodes with a between-row separation of $600 \mu \mathrm{m}$ and a within-row separation of $240 \mu \mathrm{m}$; FHC). Electrode pairs were tested until a combination that evoked large, reliable EPSPs was found. 2PLSM imaging of Alexa Fluor 568-filled neurons was used to guide the compartment-selective pressure-pulse (Picospritzer III; Parker Hannifin) application of glutamate via patch pipettes. To estimate the extent of glutamate application, Alexa Fluor 488 was added to the ejection solution and 2PLSM movies were acquired during ejection, or the application pipette was withdrawn from the target until no response was detected. When two glutamate application pipettes were used to activate different compartments of the same neuron, identical application pipettes and pressure settings were used. Occasionally, the positions of the two application pipettes were transposed to ensure that each pipette evoked similar responses. In some cases, voltage-dependent $\mathrm{Ca}_{\mathrm{v}} 1$ channel and/or ionotropic glutamate receptor antagonists were subsequently bath applied and/or $\mathrm{Na}_{\mathrm{v}}$ channel antagonists were pressurepulse applied (as for glutamate) to reduce the contribution of each ion channel to the evoked response. After electrophysiological recording, 2PLSM $z$-series ( $0.8-1 \mu \mathrm{m}$ focal steps) of Alexa Fluor 568 -filled neurons were generated.

Drugs. $\mathrm{GABA}_{\mathrm{A}}$ and $\mathrm{GABA}_{\mathrm{B}}$ receptors were blocked with $20 \mu \mathrm{M}$ SR95531 [2-(3-carboxypropyl)-3-amino-6-(4-methoxyphenyl)pyridazinium bromide] and 1-2 $\mu \mathrm{M}$ CGP55845 [(2S)-3-[([1S]-1-[3,4-dichlorophenyl]ethyl)amino-2-hydroxypropyl] (phenylmethyl)phosphinic acid], respectively. $\mathrm{D}_{2}$-like dopamine receptors were antagonized with $10 \mu \mathrm{M}$ sulpiride. Type 1 metabotropic glutamate receptors were blocked with $50 \mu \mathrm{m}$ 7-hydroxyiminocyclopropan[b]chromen-1 $\alpha$-carboxylic acid ethyl ester. $\mathrm{Ca}_{\mathrm{v}} 1$ channels were blocked with 5-20 $\mu \mathrm{M}$ isradipine or 5-10 $\mu \mathrm{M}$ nimodipine. $\mathrm{Na}_{\mathrm{v}}$ channels were blocked with $1 \mu \mathrm{M}$ tetrodotoxin (TTX). All drugs were bath applied except for TTX, which was pressure-pulse applied. Drugs were obtained from either Ascent Scientific or Tocris Bioscience.

Anatomical reconstruction. After recording, slices were fixed in $4 \%$ paraformaldehyde [in $0.1 \mathrm{M}$ phosphate buffer (PB), $\mathrm{pH} 7.4$ ] at $4^{\circ} \mathrm{C}$. To visualize biocytin-filled neurons, fixed tissue slices were rinsed with PBS, $\mathrm{pH} 7.4$, and incubated in avidin-biotin-peroxidase complex (Vectastain Elite ABC kit; Vector Laboratories) in PBS containing 1\% normal serum, $1 \%$ bovine serum albumen, and $0.5 \%$ Triton X-100 (Sigma) overnight at room temperature. Slices were then rinsed with PBS and stained with diaminobenzidine (Vector Laboratories). At the point of optimal staining, reactions were terminated by washing with PBS and then $\mathrm{PB}(0.1 \mathrm{M}$, $\mathrm{pH}$ 7.4). Finally, slices were treated with osmium (0.4\%; Electron Microscopy Sciences) for 15-20 min, rinsed with PB several times, dehydrated in a graded series of alcohol, and mounted in resin (Durcupan; Sigma) on microscope slides. The resin was then cured for $48 \mathrm{~h}$ at $60^{\circ} \mathrm{C}$ before neurons were imaged and reconstructed using a light microscope (DM LB; Leica) equipped with a Neurolucida system (MicroBrightField).

Analysis. Data were analyzed using IgorPro 6 (Wavemetrics) and Origin Pro 8 (OriginLab Corp) software. Numerical data are reported as mean \pm SD and presented as line (paired datasets) or box plots (unpaired datasets; median, central line; mean, square; $25-75 \%$ range, box; $5-95 \%$ range, outer lines). The ages of animals that were used are reported for each dataset. Paired and unpaired statistical comparisons were made using the nonparametric Wilcoxon's signed-rank test and Mann-Whitney $U$ (MWU) test, respectively. For statistical comparisons involving multiple groups, ANOVA tests followed by Tukey's multiple comparison tests were performed. A $p$ value of $<0.05$ was used as the criterion for determining statistically significant differences. Synaptic stimulation artifacts were removed by deleting up to $1 \mathrm{~ms}$ of data for each artifact and then replacing the data with a straight line that spanned the deletion. Action potential initiation was detected as described previously (Baufre- 
A1

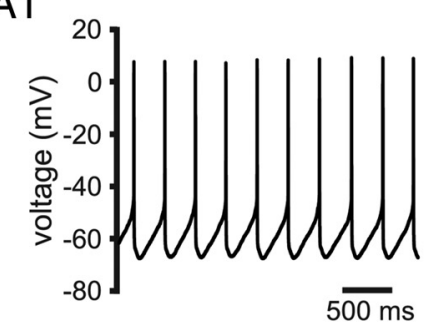

A2

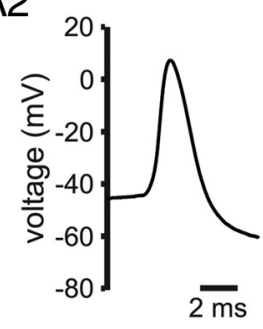

A3

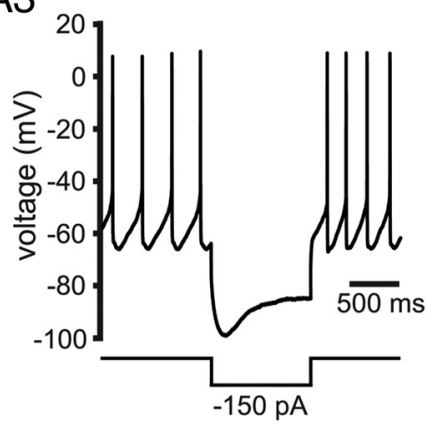

A4

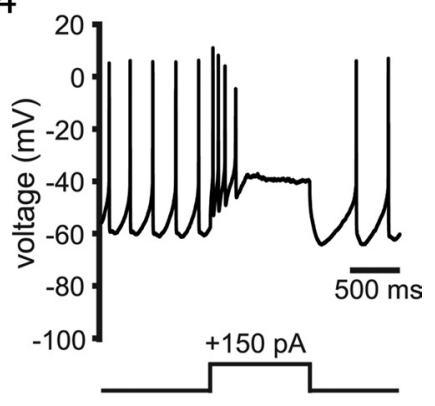

B1

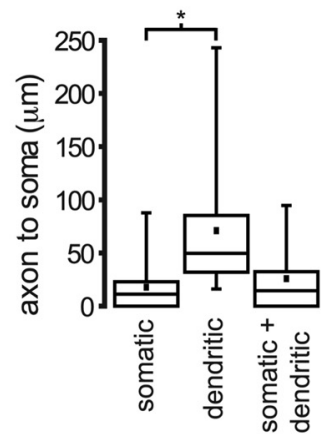

B2

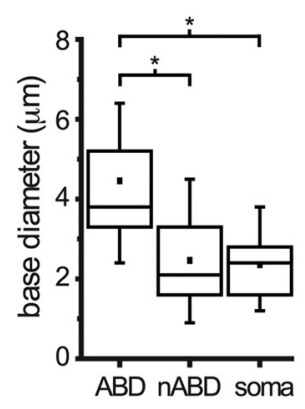

B3
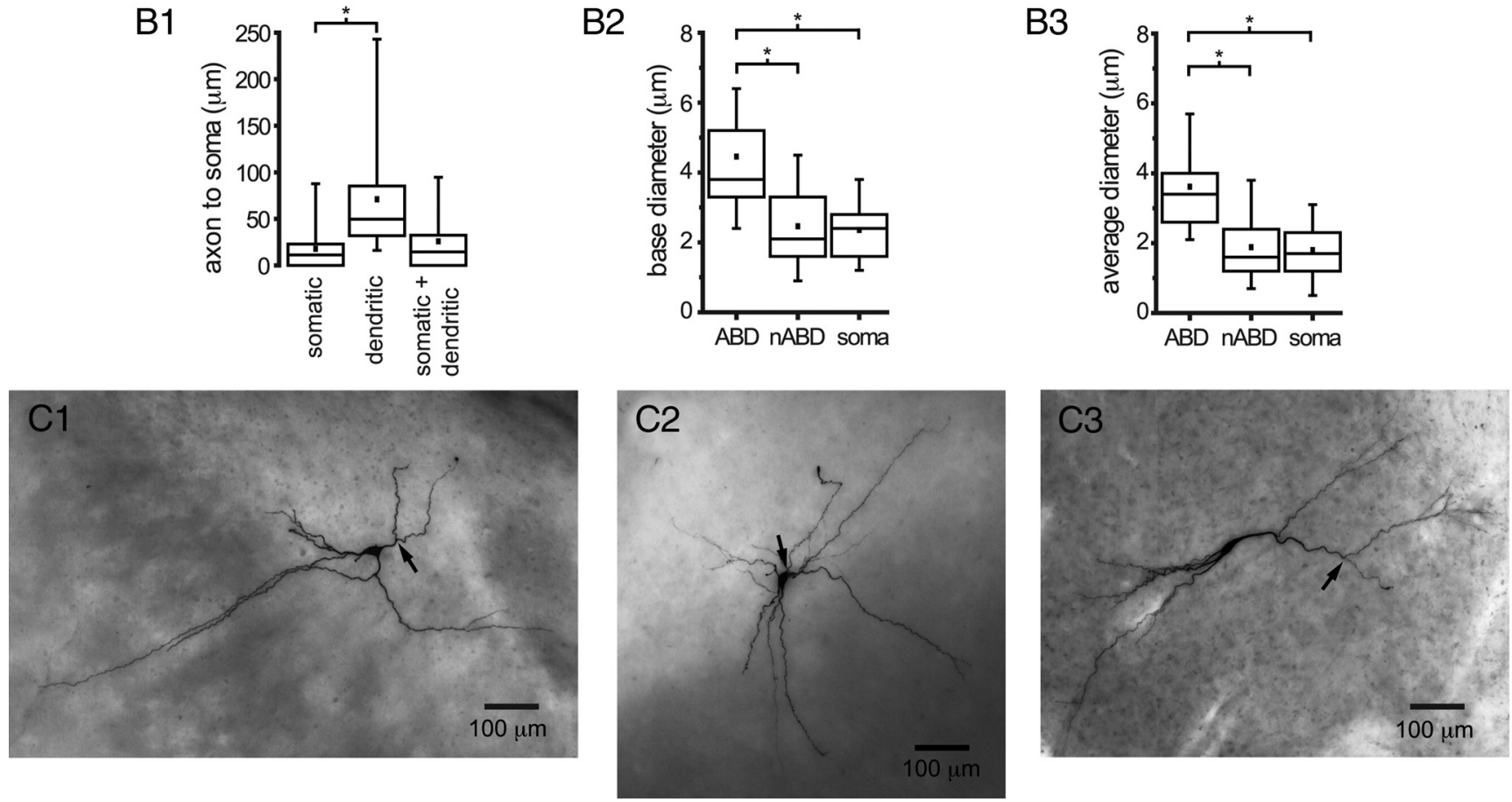

Figure 1. Physiological and morphological properties of SN DA neurons. SN DA neurons were identified by their characteristic physiological properties including slow $(<4 \mathrm{~Hz})$, autonomous firing $(\boldsymbol{A} \mathbf{1})$, broad ( $>2$ ms duration) action potentials (A2), sag in response to hyperpolarizing current injection (A3), and depolarization block (A4) in response to depolarizing current injection. B1, Selection of neurons for single somatic or dual somatic/dendritic recordings were based on the appearance of the soma or the width of proximal dendrites, respectively. The distance of the axon hillock from the soma was significantly greater for the latter selection strategy. $\mathbf{B 2}, \mathbf{B}$, The base and average diameters of the primary parts of ABDs were significantly greater than the equivalent sections of $n A B D$ s. The base and average diameters of $A B D s$ were also significantly greater than the dendrites of neurons in which the axon emerged from the soma. $C$, Examples of neurons in which the axon emerged from a proximal dendrite close $(32.9 \mu \mathrm{m})$ to the soma and the soma and a secondary dendrite far $(243 \mu \mathrm{m})$ from the soma. The axon hillock is denoted by an arrow. Note that the cut end of each axon forms a characteristic retraction ball. ${ }^{*} p<0.05$.

ton et al., 2005). Burst firing was defined as firing of a frequency greater than the mean spontaneous firing frequency $+3 \mathrm{SD}$.

\section{Results}

\section{Physiological and morphological properties of SN}

\section{DA neurons}

SN DA neurons were distinguished from other SN neurons by their characteristic physiological properties, which include slow $<4 \mathrm{~Hz}$ autonomous firing (Fig. 1A1), long-duration ( $>2 \mathrm{~ms}$ ) action potentials (Fig. 1A2), pronounced sag in response to hyperpolarization (Fig. 1A3), and cessation of action potential generation in response to depolarizing current injection (Fig. 1A4) (Richards et al., 1997). Neurons were routinely filled with biocytin for visualization after recording because the axon of SN DA neurons may arise from a variety of locations (Juraska et al., 1977; Preston et al., 1981; Grace and Bunney, 1983a,b; Tepper et al., 1987; Häusser et al., 1995; Gentet and Williams, 2007), which presumably has fundamental implications for the manner in which synaptic inputs are integrated. Our data supported previous findings that the axon originated from a dendrite in the majority of cases (73\%; 48 of 66 neurons). The healthy appearance of the soma was most commonly used to select neurons for recording $(n=56)$. In a subset of neurons, in which dendrites were also targeted for recording, neurons that additionally possessed largediameter dendrites were selected $(n=10)$. Interestingly, the axon of neurons selected for somatic criteria alone emerged from the soma $(32 \%)$ or a dendrite $(68 \%)$, whereas the axon invariably originated from a dendrite in neurons selected for large-diameter dendrites. Thus, the axon emerged from a location relatively proximal to the soma when the somatic search strategy was used (somatic strategy, $17.8 \pm 23.5 \mu \mathrm{m}, n=56$; dendritic strategy, $71.0 \pm 65.4 \mu \mathrm{m}, n=10 ; p<0.05$, MWU test) (Fig. 1 B1). Furthermore, the axon emerged from a relatively proximal part of the axon bearing dendrite (ABD) when the somatic search strategy was used (somatic strategy, $26.2 \pm 24.2 \mu \mathrm{m}, n=38$; dendritic 
A1

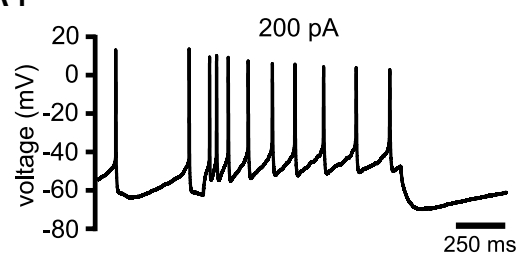

B1

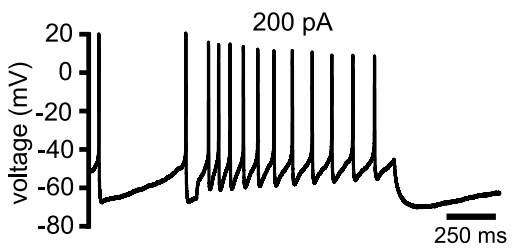

C1

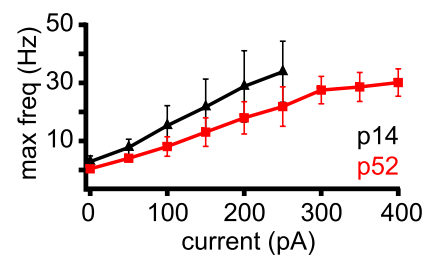

A2

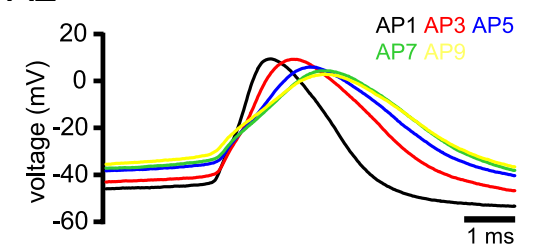

B2

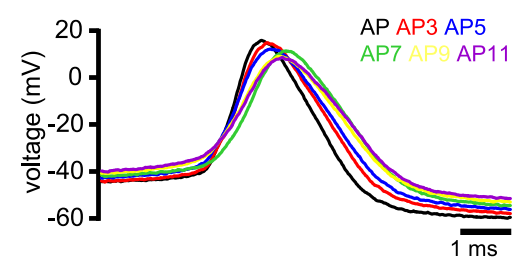

A3

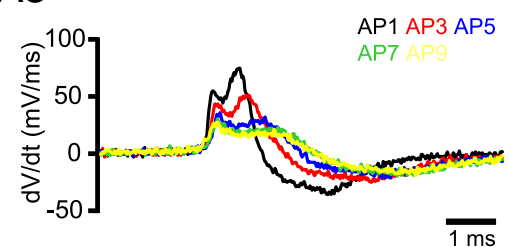

B3

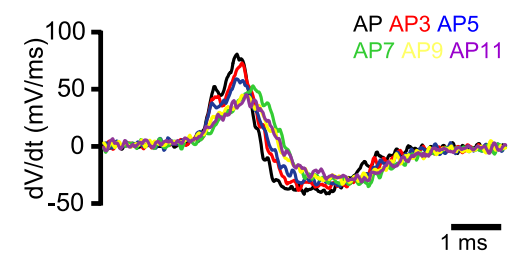

Figure 2. Somatic current generation generates a burst of action potentials. $\boldsymbol{A}-\boldsymbol{C}$, Action potential bursts evoked by somatic current injection in juvenile $(\boldsymbol{A}, \boldsymbol{C} ; \mathrm{P} 14 \pm \mathrm{P} 1)$ and more mature $(\boldsymbol{B}$, C; P52 \pm P7) SN DA neurons. A1, B1, Response of representative SN DA neurons to depolarizing current injections (200 pA for $1 \mathrm{~s}$ ). A2, B2, 0verlay of selected action potentials (AP1, AP3, AP5, AP7, AP9, AP11) generated by current injection reveals a progressive decrease and increase in the amplitude and duration of action potentials, respectively. $\mathbf{A 3}, \mathbf{B} 3,0 \mathrm{verlay}$ of the first derivative of action potentials illustrated in $\mathbf{A} \mathbf{2}$ and $\mathbf{B} \mathbf{2}$ reveals the progressive reduction in the peak of the first derivative and separation of early (axonal) and later (somatic) components of action potentials. C1, C2, Maximum (max) and mean frequency (freq) of burst activity versus current amplitude. (3, C4, Number of burst action potentials (APs) and duration of evoked burst firing versus current amplitude.

strategy, $71.0 \pm 65.4 \mu \mathrm{m}, n=10 ; p<0.05$, MWU test). The relatively distal location of the axon in neurons selected for largediameter dendrites was similar to studies that also targeted dendrites for recording (Häusser et al., 1995; Gentet and Williams, 2007). To determine whether neuron selection based on dendritic diameter targeted neurons with ABDs, the diameter of $\mathrm{ABDs}$ and non-axon bearing dendrites (nABDs) were compared in a randomly selected subset of neurons. ABDs possessed a significantly larger base diameter $(4.5 \pm 1.3 \mu \mathrm{m} ; n=20)$ than nABDs $(2.5 \pm 1.1 \mu \mathrm{m} ; n=65 ; p<0.05$, ANOVA/Tukey's test $)$ (Fig. 1B2) or dendrites of neurons in which the axon emerged from the soma $(2.4 \pm 0.9 \mu \mathrm{m}, n=26$; ANOVA/Tukey's test, $p<$ 0.05) (Fig. 1 B2). Similarly, ABDs possessed a significantly larger average diameter $(3.6 \pm 1.2 \mu \mathrm{m} ; n=20$ dendrites/20 neurons) than nABDs $(1.9 \pm 1.0 \mu \mathrm{m} ; n=65$ dendrites/20 neurons; $p<$ 0.05 , ANOVA/Tukey's test) (Fig. 1 B3) or dendrites of neurons in which the axon emerged from the soma $(1.8 \pm 0.8 \mu \mathrm{m} ; n=26$ dendrites/5 neurons; $p<0.05$, ANOVA/Tukey's test) (Fig. 1 B2). Representative examples of neurons are illustrated in Figure 1C1-C3. Together, the data demonstrate that the axon emerges from the soma or a dendrite proximal to the soma in the majority of SN DA neurons, but recording strategies that target neurons with large dendritic diameters preferentially select neurons with $\mathrm{ABD}$ in which the axon emerges from a relatively distal location.

The apparent failure of SN DA neurons, in response to somatic current injection, to fire action potentials at frequencies or durations similar to those associated with burst firing in vivo (Grace and Bunney, 1983b; Yung et al., 1991) has led to the proposition that synaptic inputs modulate or interact with the intrinsic properties of SN DA neurons in a unique manner to produce burst firing (Kitai et al., 1999; Kuznetsov et al., 2006). In vivo SN DA neuron action potential bursts comprise 2-10 action potentials with frequencies ranging from 12 to $30 \mathrm{~Hz}$ and are characterized by a progressive reduction in action potential amplitude, a progressive increase in action potential duration, and a progressive decrease in firing frequency (Grace and Bunney, 1983b, 1984; Freeman et al., 1985; Hyland et al., 2002). In the course of distinguishing SN DA neurons from SN GABA neurons, we observed, to our surprise, that action potential bursts evoked by somatic current injection were similar to in vivo burst firing (Fig. 2). The responses of SN DA neurons to current injection were therefore systematically analyzed and are illustrated in Figure 2. Data was obtained from juvenile $(n=20 ; \mathrm{P} 14 \pm \mathrm{P} 1)$ and more mature ( $n=6$; P52 \pm P7) SN DA neurons. Neurons were recorded in the whole-cell configuration (juvenile, $n=15$; mature, $n=6$ ) and the less invasive perforated configuration (juvenile, $n=$ 5 ). Data obtained from juvenile neurons in each recording configuration were similar and therefore pooled. Both juvenile and mature neurons readily generated action potential bursts. The pattern of evoked firing in vitro therefore suggests that SN DA neurons, if sufficiently depolarized, possess intrinsic membrane properties that are adequate for the generation of in vivo-like burst firing.

Burst firing can be generated by glutamatergic activation of both somatic and dendritic compartments

The duration of SK channel current in the large-diameter somatic compartment, in which $\mathrm{Ca}^{2+}$ is cleared relatively slowly, has been suggested to set an upper limit on both the frequency of autonomous firing and firing in response to somatic current injection 
A1

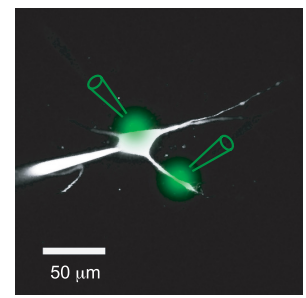

A2

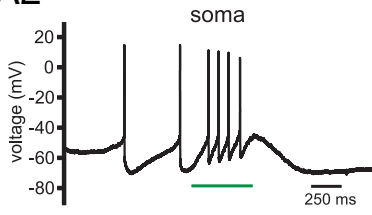

dendrite
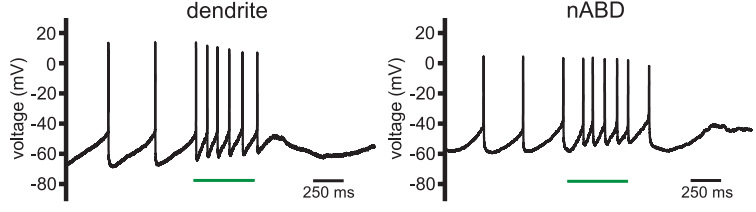

E
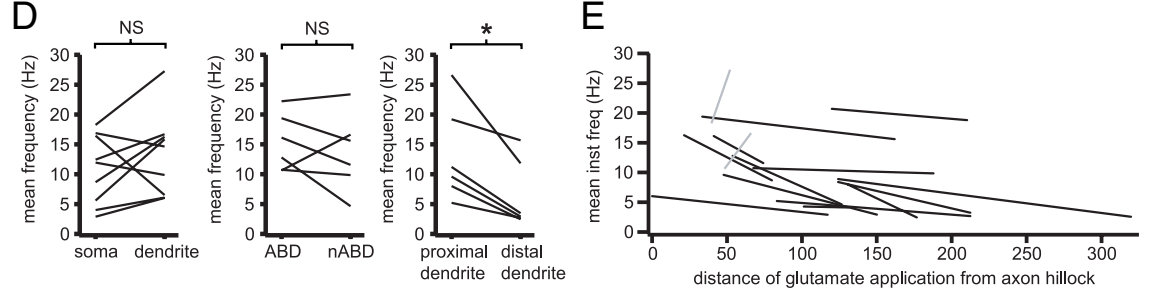

Figure 3. The intensity of glutamate-evoked activity is inversely related to the distance of glutamate application from the axon. Glutamate was pressure-pulse applied to specific compartments of SN DA neurons in three distinct combinations: soma and dendrite $(\boldsymbol{A}) ; \mathrm{ABD}$ and $\mathrm{nABD}(\boldsymbol{B})$; proximal and distal sections of the same dendrite (C). $\boldsymbol{A 1}, \boldsymbol{B 1}, \mathbf{C 1}, 2 \mathrm{PLSM} \mathbf{z}$-series of neurons together with sites of glutamate application (green). The axon hillock (red arrow) was identifiable in $\mathbf{B 1}$ and $\mathbf{C 1}$. A2, B2, C2, Glutamate-evoked activity for each combination. Green line denotes time over which glutamate was applied through pressure pulses. Applications of glutamate to the soma, ABDs and non-nABDs, and proximal and distal dendrites generated burst firing. $D, E$, Population data. Each line denotes an individual neuron. $\boldsymbol{D}$, The frequencies of activity evoked by somatic versus dendritic or $A B D$ versus $n A B D$ applications of glutamate were not significantly different. However, relatively proximal applications of glutamate generated significantly higher-frequency firing than more distal dendritic applications. $\boldsymbol{E}$, Replotting of data with respect to distance of glutamate application from the axon reveals that, in the majority of neurons, glutamate applications relatively proximal to the axon generated higher-frequency activity than more distal applications (black lines). In only two neurons (gray lines) was an opposite trend observed. ${ }^{*} p<0.05$.

Table 1. Generation of burst firing in SN DA neurons by compartment-specific application of glutamate

\begin{tabular}{lclll}
\hline & $\begin{array}{l}\text { Maximum } \\
\text { frequency (Hz) }\end{array}$ & $\begin{array}{l}\text { Mean } \\
\text { frequency (Hz) }\end{array}$ & $\begin{array}{l}\text { Number } \\
\text { of APs }\end{array}$ & $\begin{array}{l}\text { Burst } \\
\text { duration (ms) }\end{array}$ \\
\hline $\begin{array}{l}\text { Dendrite } \\
\text { Soma }\end{array}$ & $14.7 \pm 9.6$ & $10.8 \pm 5.8$ & $5.0 \pm 2.4$ & $417 \pm 69$ \\
$(n=9 ; \mathrm{P} 20 \pm \mathrm{P} 3)$ & $17.0 \pm 9.2$ & $13.2 \pm 6.9$ & $5.5 \pm 2.2$ & $378 \pm 117$ \\
$\begin{array}{l}\mathrm{ABD} \\
\mathrm{nABD}\end{array}$ & $20.9 \pm 5.2$ & $15.3 \pm 4.8$ & $6.9 \pm 1.1$ & $471 \pm 126$ \\
$(n=6 ; \mathrm{P} 18 \pm \mathrm{P} 4)$ & $19.1 \pm 9.4$ & $13.6 \pm 6.4$ & $6.6 \pm 2.1$ & $537 \pm 64$ \\
$\begin{array}{l}\text { Proximal dendrite } \\
\text { Distal dendrite } \\
(n=6 ; \mathrm{P} 20 \pm \mathrm{P} 4)\end{array}$ & $17.9 \pm 11.8$ & $13.3 \pm 8.0$ & $6.4 \pm 1.3$ & $690 \pm 284$ \\
\hline
\end{tabular}

APs, Action potentials. ${ }^{*} p<0.05$.

(Wilson and Callaway, 2000; Kuznetsov et al., 2006). In contrast, the relatively short duration of $\mathrm{Ca}^{2+}$ disposal in small-diameter dendrites (because of their higher surface area/volume ratio) has been proposed to confer dendrites with the capability to support high-frequency firing especially if oscillatory dendritic $\mathrm{Ca}_{\mathrm{v}}$ and $\mathrm{Na}_{\mathrm{v}}$ channel currents are amplified by synaptic activation of
NMDA receptors (Wilson and Callaway, 2000; Kuznetsov et al., 2006). Thus, a prediction of the model is that excitatory glutamatergic inputs to proximal, largediameter compartments will evoke lowerfrequency firing than inputs to more distal, small-diameter compartments. To test this prediction, glutamate was focally applied to SN DA neurons in a compartment-specific manner under the visual guidance of 2PLSM or conventional microscopy. Glutamate application pipettes were positioned in one of three configurations: soma and dendrite; $\mathrm{ABD}$ or $\mathrm{nABD}$; or proximal and distal parts of the same dendrite (Fig. 3). Application of glutamate to the soma or dendrites $(n=$ $9)$ or to the ABD or nABDs $(n=6)$ of individual neurons generated bursts of action potentials that were similar (Fig. $3 A, B, D$, Table 1$)$. In contrast, application of glutamate to a proximal section of dendrite generated higher-frequency burst firing than more distal application of glutamate to the same dendrite in each of six neurons tested (Fig. 3C,D, Table 1). Together, these data demonstrate that glutamatergic excitation of somatic, $\mathrm{ABD} / \mathrm{nABD}$, and proximal/distal dendritic compartments can generate burst firing in SN DA neurons. However, excitation of proximal compartments more effectively drives firing than excitation of distal compartments. Because these findings are inconsistent with the coupled oscillator model of synaptic integration (Kuznetsov et al., 2006), we next studied the relationship between the effectiveness of glutamate application and the distance of glutamate application from the axon. In the majority of neurons, applications of glutamate relatively proximal to the axon generated more intense burst firing than more distal applications (Fig. 3E). Together, these data suggest that the efficacy of excitation is inversely related to the distance from the axon, as suggested by a previous modeling study (Häusser et al., 1995).

\section{$\mathrm{Ca}_{\mathrm{v}} 1$ channels contribute to but are not essential for burst firing in SN DA neurons}

Dendritic $\mathrm{Ca}_{\mathrm{v}} 1$ channels have been proposed to be critical for high-frequency burst firing in SN DA neurons (Ping and Shepard, 1999; Shepard and Stump, 1999; Johnson and Wu, 2004; Kuznetsov et al., 2006). To test this proposition, burst firing was evoked by local electrical stimulation $(100 \mathrm{~Hz}$ for $1 \mathrm{~s})$ of excitatory afferents in the absence and presence of 5-10 $\mu \mathrm{M}$ nimodipine, a selective $\mathrm{Ca}_{\mathrm{v}} 1$ channel blocker. In these experiments, the perforated patch configuration was used. Nimodipine application significantly but modestly reduced evoked burst firing but did not abolish it (Fig. 4A, C1, Table 2). To discount the contribution of presynaptic $\mathrm{Ca}_{\mathrm{v}} 1$ channels, the effects of $\mathrm{Ca}_{\mathrm{v}} 1$ channel blockade on bursts that were generated by dendritic application of glutamate were also tested in SN DA neurons that were recorded in the whole-cell or cell-attached configuration. Bath ap- 
plication of the $\mathrm{Ca}_{\mathrm{v}} 1$ channel antagonist isradipine $(5-20 \mu \mathrm{M})$ produced a similar significant but modest reduction in the intensity of glutamate-evoked burst firing (Fig. $4 B, C 2$, Table 2). It is possible that the relatively modest effects of $\mathrm{Ca}_{\mathrm{v}} 1$ channel blockade were attributable to the relatively juvenile nature of recorded SN DA neurons $(n=12$; $\mathrm{P} 21 \pm \mathrm{P} 4)$. However, isradipine $(10 \mu \mathrm{M})$ application also failed to abolish glutamate evoked burst firing in more mature neurons $(n=5 ; \mathrm{P} 42 \pm \mathrm{P} 2)$ (supplemental Fig. S1, Table S1, available at www.jneurosci.org as supplemental material).

Although application of dihydropyridines significantly reduced the intensity of burst firing in SN DA neurons, we observed a less consistent effect of $\mathrm{Ca}_{\mathrm{v}} 1$ channel blockade on autonomous activity than some (Nedergaard et al., 1993; Mercuri et al., 1994) but not all (Fujimura and Matsuda, 1989; Shepard and Stump, 1999; Kim et al., 2007; Puopolo et al., 2007) studies have reported. After 10-15 min dihydropyridine application, the frequency of autonomous activity decreased in eight neurons and increased in eight neurons, and the regularity of firing decreased in 11 neurons and increased in five neurons. Overall, the effects were not statistically significant (control frequency, $2.9 \pm 1.4 \mathrm{~Hz}, n=16$; dihydropyridine frequency, $2.4 \pm 1.7 \mathrm{~Hz}, n=16$; control coefficient of variation, $0.12 \pm 0.12$; dihydropyridine coefficient of variation, $0.30 \pm 0.47$ )

To specifically assess the role of $\mathrm{Ca}_{\mathrm{v}} 1.3$ channels in burst firing, synaptic stimulation-evoked and exogenous glutamate-evoked burst firing were compared in control mice (BAC $\mathrm{D}_{2}$ EGFP Cacna1d wild-type) and mice with the genetic deletion of $\mathrm{Ca}_{\mathrm{v}} 1.3$ channels (BAC D 2 EGFP Cacnald knock-out) (Day et al., 2006) through whole-cell and cell-attached recording. Synaptic stimulation $(50 \mathrm{~Hz}$ for $500 \mathrm{~ms}$ ) generated action potential bursts in Cacnald wild-type and knock-out neurons that were not significantly different (Fig. 5A, Table 3). Similarly somatic or proximal dendritic application of glutamate $(50 \mathrm{~Hz}$ for $500 \mathrm{~ms}$ ) generated burst firing in Cacnald wild-type and knock-out neurons that was not significantly different (Fig. 5B, Table 3 ). In line with previous findings in rats (Morikawa et al., 2003; Blythe et al., 2007), synaptic stimulation-evoked and exogenous glutamateevoked burst firing in mouse SN DA neurons was entirely eliminated by bath application of AMPA and NMDA receptor antagonists (data not shown). Together, the data suggest that $\mathrm{Ca}_{\mathrm{v}} 1$ channels may contribute to but are not essential for burst firing in SN DA neurons.

\section{The site of action potential initiation is not altered during burst firing}

Although current injection generated action potentials are initiated in the axon of SN DA neurons (Häusser et al., 1995; Gentet and Williams, 2007), it has been predicted that synaptic input acting through NMDA receptors shifts the site of action potential initiation to dendrites during burst firing (Kuznetsov et al., 2006). Indeed action potentials actively propagate in SN DA neuron dendrites (Häusser et al., 1995; Gentet and Williams, 2007), and their morphology is compatible with action potential gener-
Table 2. Application of $\mathrm{Ca}_{\mathrm{v}} 1$ channel antagonists reduces the intensity of synaptic stimulation-evoked and exogenous glutamate-evoked burst firing in SN DA neurons

\begin{tabular}{lllll}
\hline & $\begin{array}{l}\text { Maximum } \\
\text { frequency (Hz) }\end{array}$ & $\begin{array}{l}\text { Mean } \\
\text { frequency }(\mathrm{Hz})\end{array}$ & $\begin{array}{l}\text { Number } \\
\text { of APs }\end{array}$ & $\begin{array}{l}\text { Burst } \\
\text { duration (ms) }\end{array}$ \\
\hline $\begin{array}{l}\text { Stimulation, control } \\
\text { Stimulation, nimodipine }\end{array}$ & $27.6 \pm 12.1$ & $11.7 \pm 3.1$ & $10.4 \pm 2.9$ & $1088 \pm 17.4^{*}$ \\
$\begin{array}{l}(n=8 ; \mathrm{P} 17 \pm \mathrm{P} 1) \\
\text { Glutamate, control }\end{array}$ & $10.7 \pm 3.3^{*}$ & $9.3 \pm 3.2^{*}$ & $956 \pm 163^{*}$ \\
$\begin{array}{l}\text { Glutamate, isradipine } \\
(n=12 ; \mathrm{P} 21 \pm \mathrm{P} 4)\end{array}$ & $11.4 \pm 7.0^{*}$ & $11.1 \pm 3.0$ & $6.2 \pm 1.6$ & $546 \pm 105$ \\
& & $9.2 \pm 4.8^{*}$ & $4.7 \pm 1.8^{*}$ & $454 \pm 131^{*}$ \\
\hline
\end{tabular}

APs, Action potentials. ${ }^{*} p<0.05$

ation in dendrites (Vetter et al., 2001). To address this prediction, simultaneous somatic and dendritic whole-cell patch-clamp recordings of SN DA neurons were performed during spontaneous firing and synaptic stimulation-evoked burst firing $(50 \mathrm{~Hz}$ for $500 \mathrm{~ms}$ ) to determine the relative timing of action potential initiation. Consistent with previous findings, we found that spontaneously generated action potentials were first detected with recording electrodes that were placed on $\mathrm{ABD}$ s close to the axon hillock $(n=5)$ (Fig. $6 A, C$, Table 4$)$. Furthermore, the relative timing of $\mathrm{ABD}$ and somatic action potentials was not altered during synaptic stimulation-evoked burst firing (Fig. 6A, $C$, Table 4). Consistent with axonal initiation of action potentials, spontaneous action potentials were detected in nABDs after the detection of somatic action potentials $(n=3)$, and the relative timing of $\mathrm{nABD}$ and somatic action potentials was also not altered during synaptic stimulation-evoked burst firing (Fig. 6B, $C$, Table 4).

To further test for the site of initiation of action potentials during burst firing, TTX was applied either at the site of dendritic glutamate application or in the region of the axon hillock and 
A1

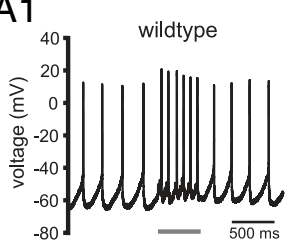

A2

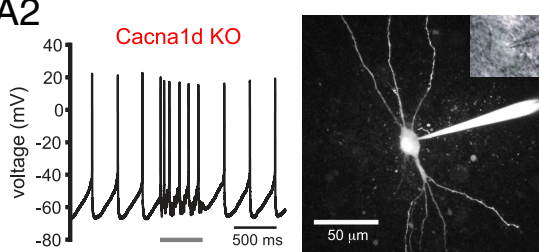

A3
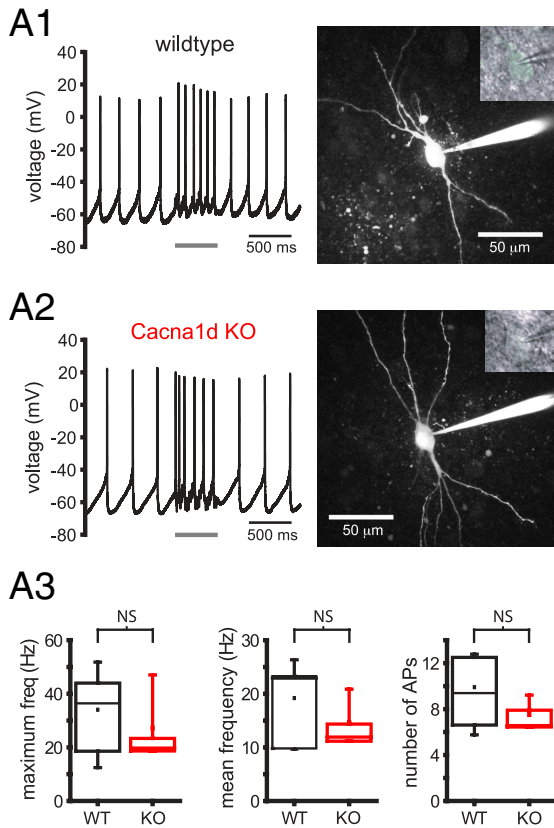

B1

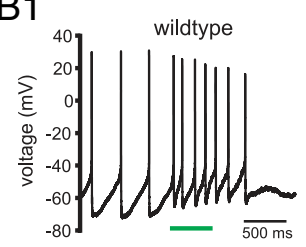

B2

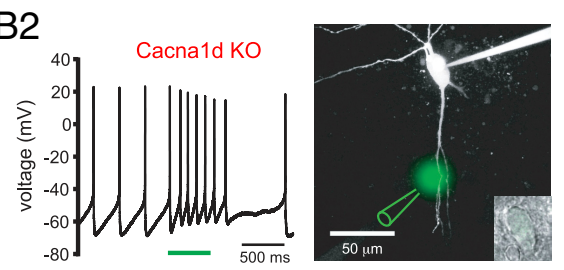

B3

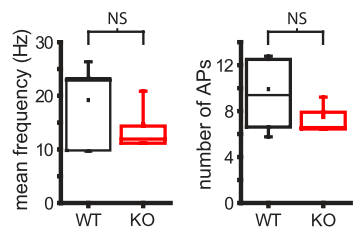

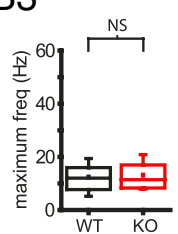

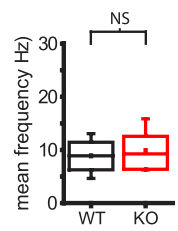

Figure 5. Synaptic stimulation or dendritic application of glutamate generates burst firing in BAC $D_{2}$ EGFP Cacna 1d wild-type/ knock-out SN DA neurons. Local synaptic stimulation ( $\boldsymbol{A}$, gray) or dendritic pressure-pulse application of glutamate $(\boldsymbol{B}$, green) generated burst firing in SN DA neurons derived from wild type (WT; $\boldsymbol{A}$ 1, B1) and Cacna1d knock-out (A2, B2) mice. 2PLSMz-series of each recorded neuron are adjacent to their respective electrophysiological records. The locations of glutamate application pipettes (green) are denoted. Insets, Overlays of Dodt contrast and EGFP fluorescent images confirm that each recorded neuron was BAC $D_{2}$ EGFP positive. A3, B3, Population data. Burst firing was not significantly different for any parameter in WT and Cacna1d knock-out mice. APs, Action potentials; freq, frequency; K0, knock-out; NS, not significant.

Table 3. Synaptic stimulation-evoked and exogenous glutamate-evoked burst firing in Cacna1d wild-type/knock-out SN DA neurons

\begin{tabular}{llll}
\hline & $\begin{array}{l}\text { Maximum } \\
\text { frequency (Hz) }\end{array}$ & $\begin{array}{l}\text { Mean } \\
\text { frequency (Hz) }\end{array}$ & Number of APs \\
\hline $\begin{array}{l}\text { Stimulation, wild type } \\
(n=6 ; \mathrm{P} 25 \pm \mathrm{P} 0)\end{array}$ & $34.0 \pm 15.3$ & $19.2 \pm 7.5$ & $9.9 \pm 3.2$ \\
$\begin{array}{l}\text { Stimulation, knock-0ut } \\
(n=4 ; \mathrm{P} 28 \pm \mathrm{P} 1)\end{array}$ & $27.2 \pm 13.4$ & $14.6 \pm 4.4$ & $7.5 \pm 1.3$ \\
$\begin{array}{l}\text { Glutamate, wild type } \\
(n=11 ; \mathrm{P} 25 \pm \mathrm{P} 3)\end{array}$ & $12.4 \pm 4.7$ & $8.9 \pm 2.6$ & $6.7 \pm 1.0$ \\
$\begin{array}{l}\text { Glutamate, knock-0ut } \\
(n=9 ; \mathrm{P} 25 \pm \mathrm{P} 2)\end{array}$ & $13.1 \pm 5.1$ & $9.9 \pm 3.6$ & $7.4 \pm 2.6$ \\
\hline
\end{tabular}

APs, Action potentials.

soma. Neurons $(n=15 ; \mathrm{P} 21 \pm \mathrm{P} 2)$ were recorded in the somatic whole-cell or cell-attached configurations. Application of TTX to the site of dendritic excitation did not alter the frequency, latency, or threshold of glutamate-evoked burst firing (Fig. 7A, Table 5) but did lead to a slight but significant reduction in the number of action potentials per burst (Fig. 7A, Table 5) (application of vehicle alone to the site of dendritic excitation had no effect on glutamate-evoked activity; data not shown). In contrast, application of TTX to the axo-somatic region impaired autonomous activity and dramatically reduced burst firing (Fig. 7B, Table 5). Thus, axo-somatic TTX application significantly decreased the maximum frequency of burst firing and the number of action potentials associated with burst firing and increased the latency to burst firing (Fig. 7B, Table 5). Axo-somatic TTX application also elevated the threshold of action potentials evoked by dendritic glutamate application in each of five neurons recorded in the whole-cell configuration. Anatomical reconstruction of neurons in which the axon could be identified confirmed that
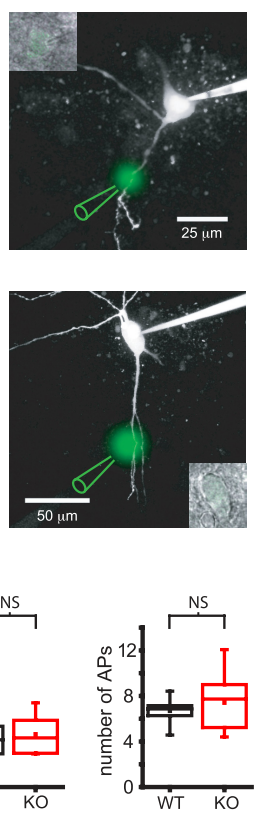

dendritic TTX applications were significantly further from the axon hillock than axo-somatic applications (dendritic TTX, $110.0 \pm 26.4 \mu \mathrm{m}, n=7$; axo-somatic TTX, $23.7 \pm 10.9 \mu \mathrm{m}, n=$ 5; $p<0.05$, MWU test). The relatively powerful effects of axo-somatic versus dendritic TTX application on glutamate-evoked action potential bursts were also confirmed in more mature $(n=4 ; \mathrm{P} 47 \pm \mathrm{P} 3)$ SN DA neurons (supplemental Fig. S2, Table S2, available at www.jneurosci.org as supplemental material). Together, these data suggest that spontaneous and synaptic stimulation-evoked and glutamate-evoked burst firing are initiated in the axon of SN DA neurons and dendritic excitation does not shift the site of initiation to other compartments.

\section{Discussion}

The axon typically emerges from a large-diameter, proximal dendrite Previous studies have reported that the axon of SN DA neurons emerges from the soma or a dendrite (Juraska et al., 1977; Preston et al., 1981; Grace and Bunney, 1983a; Tepper et al., 1987; Häusser et al., 1995; Gentet and Williams, 2007). However, a wide range of axon-soma separations have been documented ranging from short (15-30 $\mu \mathrm{m})$ (Grace and Bunney, 1983a), long (69-258 $\mu \mathrm{m})$ (Gentet and Williams, 2007), and highly variable $(0-240 \mu \mathrm{m})$ (Häusser et al., 1995). A possible reason for the variability between studies is that neurons were sampled blindly (e.g., Golgi labeling or in vivo recording studies) or targeted according to the suitability of their somata or dendrites for patch-clamp recording. Indeed, we show that the axon-soma separation of neurons selected for recording from large-diameter dendrites was significantly greater $(71.0 \pm$ $65.4 \mu \mathrm{m})$ than neurons selected for their somatic appearance alone $(17.8 \pm 23.5 \mu \mathrm{m})$. This sampling bias presumably arises because SN DA neuron axons emerge from the largest-diameter dendrite, as suggested previously (Häusser et al., 1995; Gentet and Williams, 2007) and confirmed here. The diameter of ABDs was approximately twice as thick as nABDs. Given the average axon-soma separation and the large diameter of ABDs, the data are consistent with the conclusion that the axon of SN DA neurons typically arises from a compartment that is electrotonically close to the soma. This proximity could increase the security of action potential propagation from the axon to the soma. Indeed, axon-soma propagation failures are common in SN DA neurons when axon-soma separations exceed the mean separation reported here by a factor of 2-3 (Gentet and Williams, 2007).

\section{Somatic current injection generates bursts of action} potentials that are similar in form to those observed in vivo In anesthetized or awake rats, SN DA neuron action potential bursts are associated with a progressive reduction in action potential amplitude, a progressive increase in action potential duration, and a progressive decrease in instantaneous frequency and are comprised of 2-10 action potentials with an instantaneous frequency ranging from 12 to $30 \mathrm{~Hz}$ (Grace and Bunney, 1983b, 

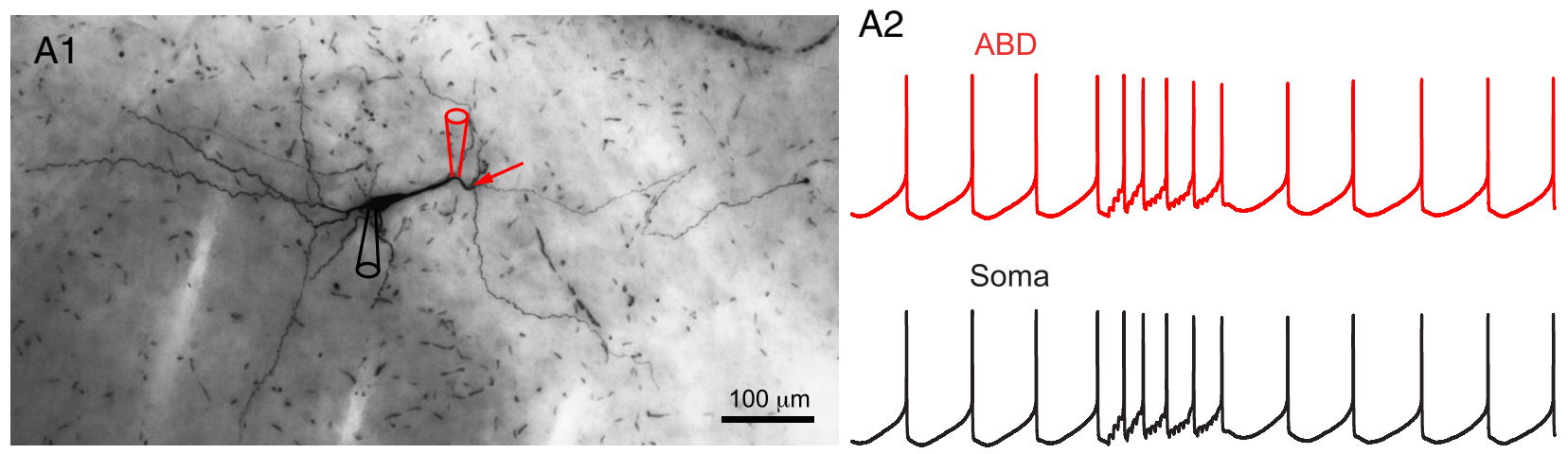

Soma
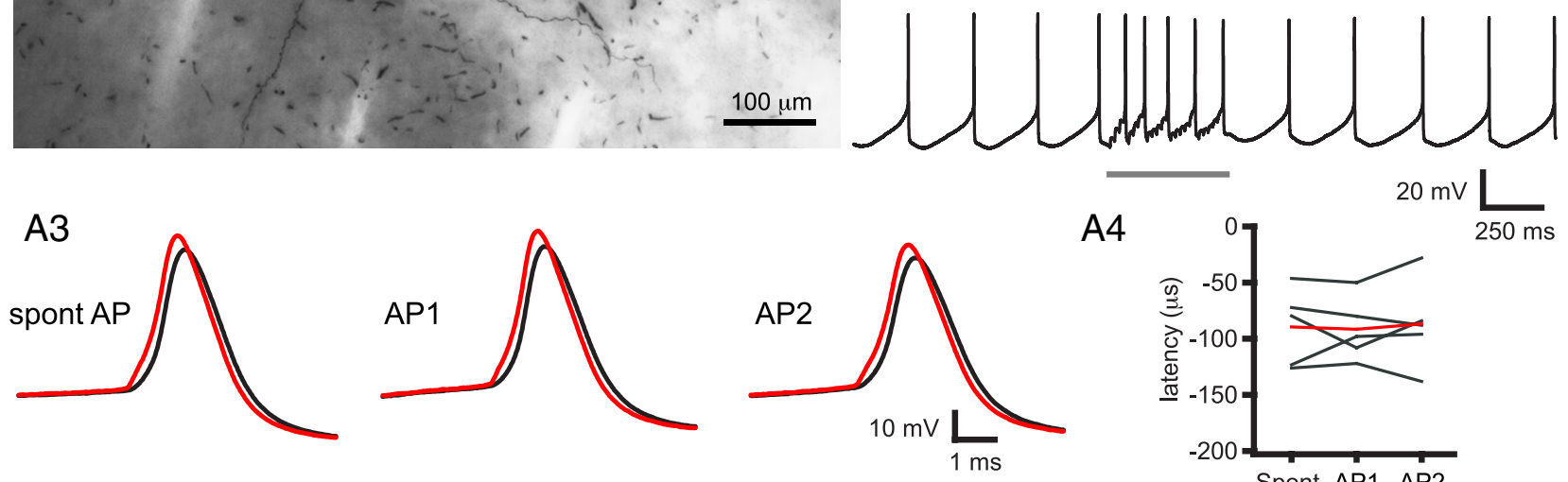

A4
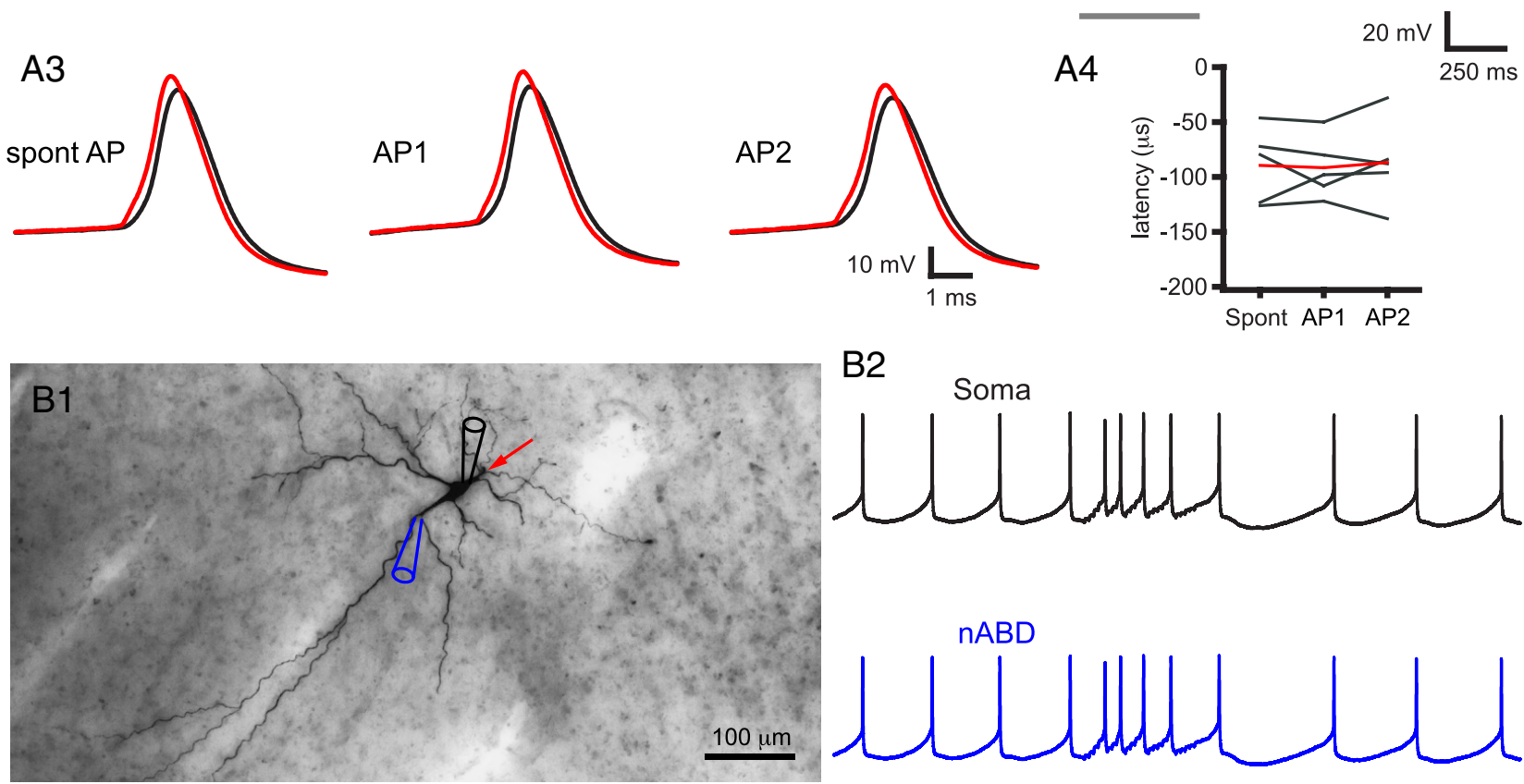

B2

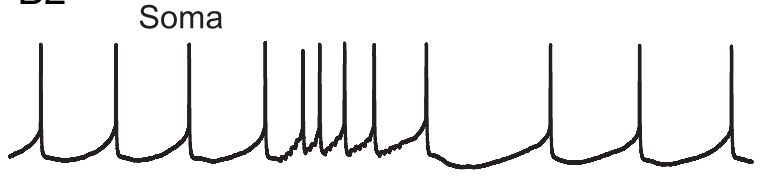

B3

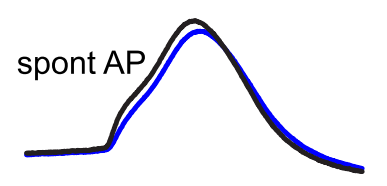

C

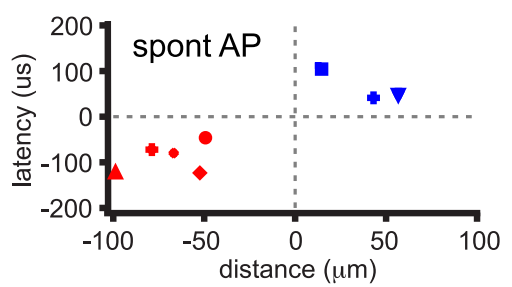

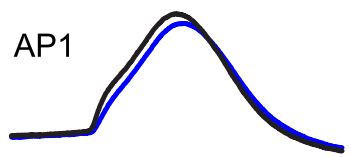
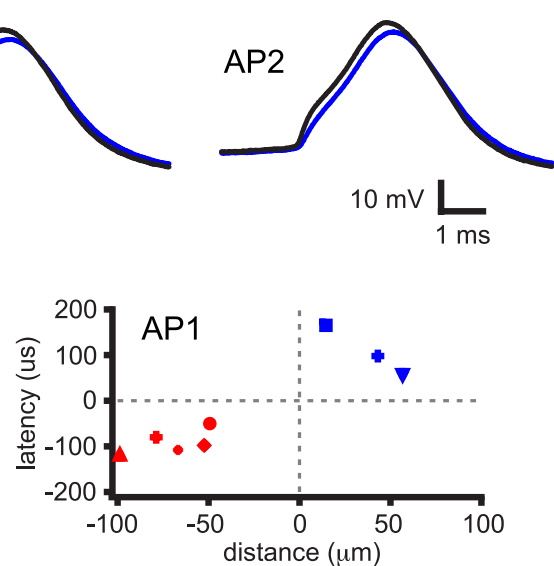

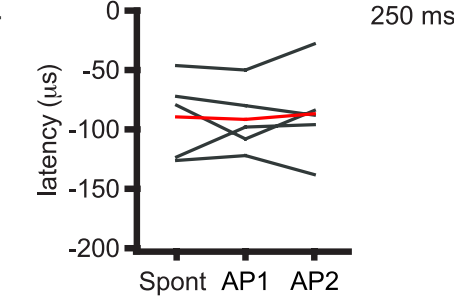

Figure 6. The site of action potential initiation does not shift during synaptic stimulation-evoked burst firing. $\boldsymbol{A}-\boldsymbol{C}$, Simultaneous recordings from the soma (black) and an $A B D$ (red) or the soma and a $\mathrm{nABD}$ (blue) were used to compare the relative timing of action potentials (time of dendritic action potential - time of somatic action potential) during spontaneous firing and synaptic stimulation-evoked action potential bursts. Spontaneous action potentials (spont AP) and the first (AP1) and second (AP2) action potentials of synaptic stimulationevoked action potential bursts are indicated. $\boldsymbol{A} \mathbf{1}, \boldsymbol{B} \mathbf{1}$, Photomontages of recorded, biocytin-labeled neurons together with sites of somatic and dendritic recording locations relative to the axon hillock (red arrow). A2, B2, Local electrical stimulation at $50 \mathrm{~Hz}$ for $500 \mathrm{~ms}$ (gray bar) generated a burst of action potentials in each recorded neuron. $\boldsymbol{A} \mathbf{3}, \boldsymbol{A} \mathbf{4}$, Action potentials were first detected in the $A B D$ and then the soma in a representative neuron $(A 3)$ and the sample population $(A 4 ; n=5$; black lines represent individual neuron data, red line represents sample mean). $\boldsymbol{B} \mathbf{3}, \boldsymbol{B} 4$, Action potentials were recorded in the soma and then the $n A B D$ in a representative neuron $(\boldsymbol{B} \mathbf{3})$ and the sample population $(\boldsymbol{B} 4 ; n=3 ;$ black lines represent individual neuron data, blue line represents sample mean). $C$, Timing of dendritic action potentials plotted with respect to the timing of somatic action potentials versus the relative distance of the dendritic and somatic recording electrodes from the axon hillock (distance = distance of dendritic electrode from axon hillock - distance of somatic electrode from axon hillock). Individual neuron data are represented by distinct symbols. 
Table 4. Timing of spontaneous and synaptically evoked action potentials in ABDs and $n A B D$ s relative to somatic action potentials in SN DA neurons

\begin{tabular}{lcrr}
\hline & Spontaneous $(\mu s)$ & \multicolumn{1}{c}{ Burst AP1 $(\mu s)$} & \multicolumn{1}{c}{ Burst AP2 $(\mu s)$} \\
\hline $\operatorname{ABD}(n=5 ; \mathrm{P} 13 \pm \mathrm{P} 1)$ & $-89.5 \pm 34.4$ & $-91.6 \pm 27.8$ & $-86.8 \pm 39.3$ \\
$\operatorname{nABD}(n=3 ; \mathrm{P} 13 \pm \mathrm{P} 1)$ & $65.6 \pm 33.8$ & $107.7 \pm 53.2$ & $110.3 \pm 40.2$
\end{tabular}

AP, Action potential. The relative timing of action potentials was calculated from the time of initiation in the dendritic compartment subtracted by the time of initiation in the somatic compartment.
1984; Freeman et al., 1985; Hyland et al., 2002). It has been suggested that somatic current injection in SN DA neurons cannot generate burst firing because of the limiting effects of SK channelmediated action potential afterhyperpolarization and $\mathrm{Na}_{\mathrm{v}}$ channel inactivation (Grace and Bunney, 1983b; Kuznetsov et al., 2006). However, our study and other studies in mature animals (Nedergaard et al., 1993; Richards et al., 1997) demonstrate that somatic depolarizing current injection can generate action potential bursts that are similar in pattern and frequency to those observed in vivo. A possible reason for this discrepancy is that intracellular recordings in vivo caused relatively greater damage to the somatic membrane than in vitro intracellular or patch-clamp recordings, thereby perturbing intrinsic properties and limiting the effectiveness of somatic current injection. Another possibility is that factors preserved by the more intact in vivo preparation, e.g., background synaptic activity contributes to the discrepancy. Together, these findings demonstrate that somatic SK channels and $\mathrm{Na}_{\mathrm{v}}$ channel inactivation do not prevent burst firing and that bursts are generated in SN DA neurons in vitro when there is sufficient depolarization.
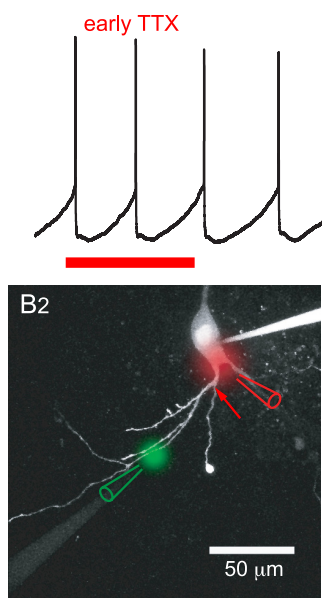

B3

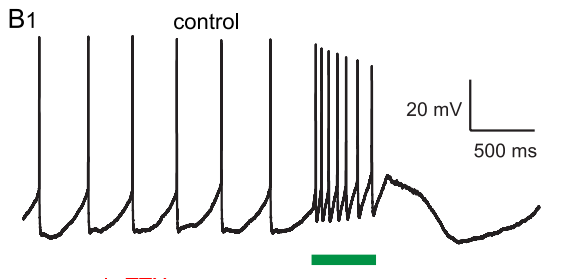

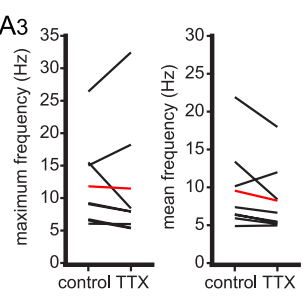

late TTX
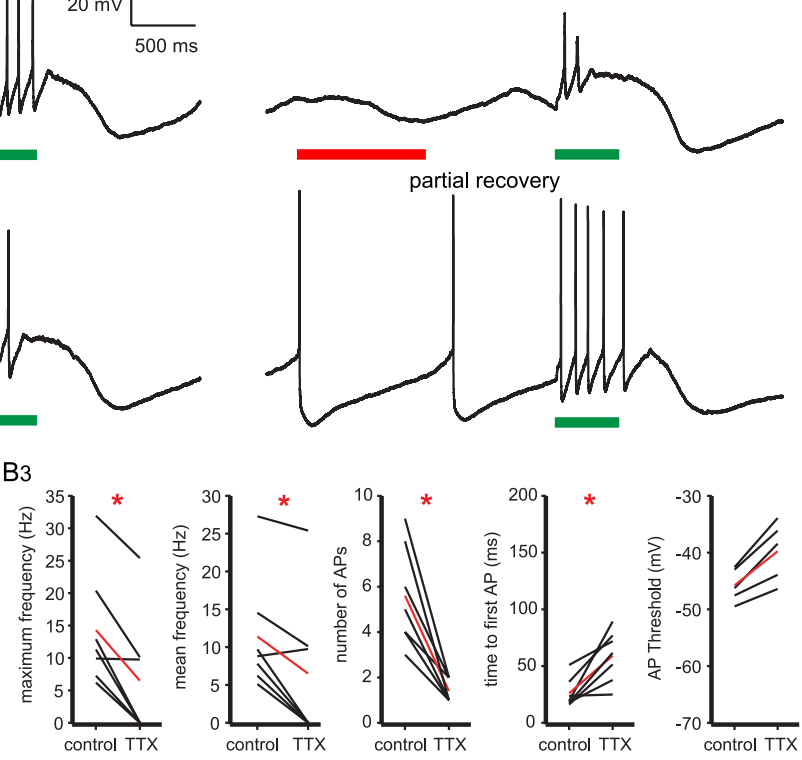

Figure 7. Initiation of action potential bursts is impaired by blockade of axo-somatic $\mathrm{Na}_{v}$ channels but not $\mathrm{Na}_{v}$ channels at the site of excitation. $\boldsymbol{A}$, Application of TTX to the site of dendritic glutamate application had a minimal effect on spontaneous and glutamate-evoked activity. A1,A2, Representative example. A1, Application of TTX (red) 1s before the dendritic pulsed application of glutamate (green) had little effect on evoked activity compared with that evoked under control conditions. A2, 2PLSM z-series with sites of TTX (red) and glutamate (green) application indicated for the example in $\mathbf{A 1}$. A3, Population data. Black lines represent individual cells, and red lines represent population mean. Dendritic TTX application significantly reduced the number of evoked action potentials (APs) but had no effect on any other parameter. $\boldsymbol{B}$, Axo-somatic application of TTX reduced spontaneous activity and the intensity of burst firing that was evoked by dendritic application of glutamate. $\boldsymbol{B} \mathbf{1}$, B2, Representative example. B1, Proximal application of TTX (red) 1 s before the dendritic application of glutamate (green) reduced spontaneous and evoked activity compared with that observed under control conditions. The reduction in firing increased with successive applications of TTX; compare early (first) and late (ninth) trials. B2, 2PLSM z-series with sites of glutamate (green) and TTX (red) application indicated for the example in B2. B3, Population data. Black lines represent individual cells, and red lines represent population means. Axo-somatic TTX application significantly (red asterisk) reduced the intensity and increased the latency of burst firing and also increased the threshold of APs in each of five neurons tested. AP, Action potential. * $p<0.05$.

\section{Glutamatergic excitation of somatic and dendritic compartments generate burst firing}

It has been proposed that excitation of either somatodendritic compartments proximal to the axon (Häusser et al., 1995) or small-diameter dendritic compartments distal to the axon of SN DA neurons more effectively generate firing (Kuznetsov et al., 2006). To experimentally test these contradictory predictions, glutamate was pressure-pulse applied under visual guidance to activate postsynaptic AMPA and NMDA receptors in a compartment-selective manner (Blythe et al., 2007). Although glutamate applied in this manner does not closely mimic the spatiotemporal profile of synaptically released transmitter, glutamatergic excitation of both SN DA neuron somata and dendrites generated bursts of action potentials that resembled those observed in vivo. Furthermore, glutamatergic excitation of proximal dendrites generated stronger firing than excitation of distal dendrites. Although glutamate application to large-diameter proximal compartments may have activated more AMPA and NMDA receptors than application to thin, distal compartments, the capability of somatic excitation to evoke burst firing is inconsistent with a profound limiting influence of somatic SK channels. These findings therefore do not support the primary prediction of the coupled oscillator model that excitation of thin, distal den- 
Table 5. Effects of dendritic or axo-somatic TTX application on dendritic glutamate-evoked burst firing in SN DA neurons

\begin{tabular}{llllll}
\hline & $\begin{array}{l}\text { Maximum } \\
\text { frequency } \\
(\mathrm{Hz})\end{array}$ & $\begin{array}{l}\text { Mean } \\
\text { frequency } \\
(\mathrm{Hz})\end{array}$ & $\begin{array}{l}\text { Number } \\
\text { of APs }\end{array}$ & $\begin{array}{l}\text { Latency } \\
(\mathrm{ms})\end{array}$ & $\begin{array}{l}\text { AP } \\
\text { threshold } \\
(\mathrm{mV})\end{array}$ \\
\hline Control & $11.8 \pm 6.9$ & $9.6 \pm 5.7$ & $5.3 \pm 1.8$ & $42.7 \pm 47.7$ & $-48.0 \pm 7.6$ \\
Dendritic TTX & $11.5 \pm 9.4$ & $8.2 \pm 4.6$ & $4.1 \pm 1.7^{*}$ & $57.2 \pm 57.4$ & $-47.0 \pm 8.4$ \\
(P21 \pm P4) & $(n=8)$ & $(n=8)$ & $(n=8)$ & $(n=8)$ & $(n=6)$ \\
Control & $14.3 \pm 9.1$ & $11.4 \pm 7.7$ & $5.6 \pm 2.2$ & $26.0 \pm 13.0$ & $-45.8 \pm 3.0$ \\
Axosomatic TTX & $6.5 \pm 9.6^{*}$ & $6.5 \pm 9.6^{*}$ & $1.4 \pm 0.5^{*}$ & $59.2 \pm 22.7^{*}$ & $-39.8 \pm 5.3$ \\
(P21 \pm P2) & $(n=7)$ & $(n=7)$ & $(n=7)$ & $(n=7)$ & $(n=5)$ \\
\hline
\end{tabular}

$\mathrm{AP}$, Action potential. ${ }^{*} p<0.05$. Discrepancies in the number of observations are because a subset of recordings was made in the cell-attached configuration in which action potential threshold cannot be measured.

drites generates higher-frequency firing than excitation of the soma (Wilson and Callaway, 2000; Kuznetsov et al., 2006). Indeed, when the location of the axon was taken into account, we found that the intensity of evoked firing was inversely related to the distance of excitation from the axon hillock. This observation is consistent with the view that inputs proximal to the axon have a relatively greater impact than more distal inputs because they occupy a "relatively privileged position," close in electrotonic terms to the presumed site of action potential initiation in the proximal axon (Häusser et al., 1995).

\section{$\mathrm{Ca}_{\mathrm{v}} \mathbf{1}$ channels contribute modestly to burst firing}

Application of dihydropyridines moderately reduced the intensity of both synaptically evoked and exogenous glutamate-evoked burst firing but did not eliminate it. In addition, action potential bursts evoked in neurons in mice with or without genetic deletion of $\mathrm{Ca}_{\mathrm{v}} 1.3$ channels were not significantly different. Together, these data imply that $\mathrm{Ca}_{\mathrm{v}} 1$ channels may contribute to but are not essential for burst firing. These data are consistent with the dihydropyridine sensitivity of apamin-induced (Shepard and Stump, 1999) but not NMDA-induced (Johnson and Wu, 2004) burst firing in SN DA neurons. The data are clearly inconsistent with the reliance on dendritic $\mathrm{Ca}_{\mathrm{v}} 1$ channel-dependent voltage oscillations for burst firing (Kuznetsov et al., 2006).

In concordance with some studies (Fujimura and Matsuda, 1989; Shepard and Stump, 1999; Kim et al., 2007; Puopolo et al., 2007) but not all studies (Nedergaard et al., 1993; Mercuri et al., 1994), the effects of $\mathrm{Ca}_{\mathrm{v}} 1$ channel blockade on spontaneous/ autonomous activity were variable. Indeed, it is becoming increasingly clear that a variety of channels contribute to autonomous firing in these neurons, including $\mathrm{Na}_{\mathrm{v}}, \mathrm{Ca}_{\mathrm{v}} 2.1, \mathrm{HCN}$, and nonselective cation channels (Grace and Onn, 1989; Neuhoff et al., 2002; Chan et al., 2007; Kim et al., 2007; Puopolo et al., 2007; Guzman et al., 2009).

\section{Dendritic $\mathrm{Na}_{\mathrm{v}}$ channels do not initiate burst firing}

Under conditions of intense synaptic excitation, some neurons are capable of generating dendritic action potentials in advance of axonal action potential initiation (Stuart et al., 1997; Golding and Spruston, 1998; Kamondi et al., 1998). Because SN DA neurons possess a high density of dendritic $\mathrm{Na}_{\mathrm{v}}$ channels and a dendritic geometry "conducive" to dendritic action potential formation and propagation (Häusser et al., 1995; Vetter et al., 2001; Gentet and Williams, 2007), it has been proposed that synaptic excitation shifts the site of action potential initiation from the axon to the site of excitation during burst firing (Kuznetsov et al., 2006). However, simultaneous recordings from the somata and dendrites of SN DA neurons during burst firing revealed that action potentials were always first detected at the site of recording closest to the axon, suggesting that action potential initiation remains fixed within that compartment. Furthermore, blockade of dendritic $\mathrm{Na}_{\mathrm{v}}$ channels close to the site of exogenous glutamate application did not reduce the intensity of burst firing, whereas blockade of $\mathrm{Na}_{\mathrm{v}}$ channels in the soma/axon hillock region significantly reduced autonomous and evoked burst firing. Thus, dendritic $\mathrm{Na}_{\mathrm{v}}$ channels do not appear to strongly boost dendritic excitation or underlie the initiation action potentials in SN DA neurons. These data are consistent with previous observations, which showed that dendritic injection of square-wave or AMPA receptor synaptic current waveforms do not shift the site of action potential initiation from the axon to the site of excitation (Häusser et al., 1995; Gentet and Williams, 2007).

\section{Functional implications}

The data are consistent with the conclusion that SN DA neurons integrate excitatory inputs in a relatively conventional manner (Eccles, 1966). Thus, action potentials are invariably initiated in the axon, and the efficacy of excitation is inversely related to its distance from the axon. Although $\mathrm{Na}_{\mathrm{v}}$ and $\mathrm{Ca}_{\mathrm{v}}$ channels are strongly expressed in the dendrites of SN DA neurons, they appear to be more important for the release of dopamine from dendrites than the boosting of excitatory inputs. Dendritic $\mathrm{Na}_{\mathrm{v}}$ channels underlie the active backpropagation of action potentials, which leads to the activation of "high voltage-activated" $\mathrm{Ca}_{\mathrm{v}} 2.2$ channels, which in turn pass $\mathrm{Ca}^{2+}$ that triggers exocytosis of dopamine (Häusser et al., 1995; Beckstead et al., 2004; Gentet and Williams, 2007). Dendritic dopamine release, through $\mathrm{D}_{2}$ dopamine receptor-GIRK (G-protein-gated inwardly rectifying $\mathrm{K}^{+}$ channel) signaling (Lacey et al., 1987; Beckstead et al., 2004), is believed to be critical for the negative feedback control of firing in SN DA neurons (Pucak and Grace, 1994). Clearly, this homeostatic mechanism would be compromised if dopamine release was generated directly by synaptic excitation and was not a reflection of axonal activity. If dendritic $\mathrm{Ca}_{\mathrm{v}} 1$ channels are not essential for firing or dendritic dopamine release (Chen et al., 2006), what function do they serve? This is a critical question because recent studies suggest that blockade of $\mathrm{Ca}_{\mathrm{v}} 1$ channels reduces the vulnerability of SN DA neurons in Parkinson's disease (Chan et al., 2007; Becker et al., 2008). This study does not speak to the neuroprotective mechanism, but it does suggest that therapies based on $\mathrm{Ca}_{\mathrm{v}} 1$ channel blockade will not prevent burst firing in SN DA neurons.

\section{References}

Baufreton J, Atherton JF, Surmeier DJ, Bevan MD (2005) Enhancement of excitatory synaptic integration by GABAergic inhibition in the subthalamic nucleus. J Neurosci 25:8505-8517.

Becker C, Jick SS, Meier CR (2008) Use of antihypertensives and the risk of Parkinson disease. Neurology 70:1438-1444.

Beckstead MJ, Grandy DK, Wickman K, Williams JT (2004) Vesicular dopamine release elicits an inhibitory postsynaptic current in midbrain dopamine neurons. Neuron 42:939-946.

Blythe SN, Atherton JF, Bevan MD (2007) Synaptic activation of dendritic AMPA and NMDA receptors generates transient high-frequency firing in substantia nigra dopamine neurons in vitro. J Neurophysiol 97:2837-2850.

Centonze D, Picconi B, Gubellini P, Bernardi G, Calabresi P (2001) Dopaminergic control of synaptic plasticity in the dorsal striatum. Eur J Neurosci 13:1071-1077.

Chan CS, Guzman JN, Ilijic E, Mercer JN, Rick C, Tkatch T, Meredith GE, Surmeier DJ (2007) "Rejuvenation" protects neurons in mouse models of Parkinson's disease. Nature 447:1081-1086.

Chen BT, Moran KA, Avshalumov MV, Rice ME (2006) Limited regulation of somatodendritic dopamine release by voltage-sensitive Ca channels contrasted with strong regulation of axonal dopamine release. J Neurochem 96:645-655. 
Day M, Wang Z, Ding J, An X, Ingham CA, Shering AF, Wokosin D, Ilijic E, Sun Z, Sampson AR, Mugnaini E, Deutch AY, Sesack SR, Arbuthnott GW, Surmeier DJ (2006) Selective elimination of glutamatergic synapses on striatopallidal neurons in Parkinson disease models. Nat Neurosci 9:251-259.

Eccles JC (1966) The ionic mechanisms of excitatory and inhibitory synaptic action. Ann NY Acad Sci 137:473-494.

Freeman AS, Meltzer LT, Bunney BS (1985) Firing properties of substantia nigra dopaminergic neurons in freely moving rats. Life Sci 36:1983-1994.

Fujimura K, Matsuda Y (1989) Autogenous oscillatory potentials in neurons of the guinea pig substantia nigra pars compacta in vitro. Neurosci Lett 104:53-57.

Gentet LJ, Williams SR (2007) Dopamine gates action potential backpropagation in midbrain dopaminergic neurons. J Neurosci 27:1892-1901.

Golding NL, Spruston N (1998) Dendritic sodium spikes are variable triggers of axonal action potentials in hippocampal CA1 pyramidal neurons. Neuron 21:1189-1200.

Gonon FG (1988) Nonlinear relationship between impulse flow and dopamine released by rat midbrain dopaminergic neurons as studied by in vivo electrochemistry. Neuroscience 24:19-28.

Grace AA, Bunney BS (1980) Nigral dopamine neurons: intracellular recording and identification with L-dopa injection and histofluorescence. Science 210:654-656.

Grace AA, Bunney BS (1983a) Intracellular and extracellular electrophysiology of nigral dopaminergic neurons. 1. Identification and characterization. Neuroscience 10:301-315.

Grace AA, Bunney BS (1983b) Intracellular and extracellular electrophysiology of nigral dopaminergic neurons. 2. Action potential generating mechanisms and morphological correlates. Neuroscience 10:317-331.

Grace AA, Bunney BS (1984) The control of firing pattern in nigral dopamine neurons: burst firing. J Neurosci 4:2877-2890.

Grace AA, Onn SP (1989) Morphology and electrophysiological properties of immunocytochemically identified rat dopamine neurons recorded in vitro. J Neurosci 9:3463-3481.

Guyenet PG, Aghajanian GK (1978) Antidromic identification of dopaminergic and other output neurons of the rat substantia nigra. Brain Res 150:69-84.

Guzman JN, Sánchez-Padilla J, Chan CS, Surmeier DJ (2009) Robust pacemaking in substantia nigra dopaminergic neurons. J Neurosci 29:1101111019.

Harris NC, Webb C, Greenfield SA (1989) A possible pacemaker mechanism in pars compacta neurons of the guinea-pig substantia nigra revealed by various ion channel blocking agents. Neuroscience 31:355-362.

Häusser M, Stuart G, Racca C, Sakmann B (1995) Axonal initiation and active dendritic propagation of action potentials in substantia nigra neurons. Neuron 15:637-647.

Hyland BI, Reynolds JN, Hay J, Perk CG, Miller R (2002) Firing modes of midbrain dopamine cells in the freely moving rat. Neuroscience 114:475-492.

Johnson SW, Wu YN (2004) Multiple mechanisms underlie burst firing in rat midbrain dopamine neurons in vitro. Brain Res 1019:293-296.

Juraska JM, Wilson CJ, Groves PM (1977) The substantia nigra of the rat: a Golgi study. J Comp Neurol 172:585-600.

Kamondi A, Acsády L, Buzsáki G (1998) Dendritic spikes are enhanced by cooperative network activity in the intact hippocampus. J Neurosci 18:3919-3928.

Kim SH, Choi YM, Jang JY, Chung S, Kang YK, Park MK (2007) Nonselective cation channels are essential for maintaining intracellular $\mathrm{Ca}^{2+}$ levels and spontaneous firing activity in the midbrain dopamine neurons. Pflugers Arch 455:309-321.

Kitai ST, Shepard PD, Callaway JC, Scroggs R (1999) Afferent modulation of dopamine neuron firing patterns. Curr Opin Neurobiol 9:690-697.

Kreitzer AC, Malenka RC (2007) Endocannabinoid-mediated rescue of striatal LTD and motor deficits in Parkinson's disease models. Nature 445:643-647.

Kuznetsov AS, Kopell NJ, Wilson CJ (2006) Transient high-frequency firing in a coupled-oscillator model of the mesencephalic dopaminergic neuron. J Neurophysiol 95:932-947.

Lacey MG, Mercuri NB, North RA (1987) Dopamine acts on D2 receptors to increase potassium conductance in neurones of the rat substantia nigra zona compacta. J Physiol 392:397-416.

Liss B, Franz O, Sewing S, Bruns R, Neuhoff H, Roeper J (2001) Tuning pacemaker frequency of individual dopaminergic neurons by $\mathrm{Kv} 4.3 \mathrm{~L}$ and KChip3.1 transcription. EMBO J 20:5715-5724.

Mercuri NB, Bonci A, Calabresi P, Stratta F, Stefani A, Bernardi G (1994) Effects of dihydropyridine calcium antagonists on rat midbrain dopaminergic neurones. Br J Pharmacol 113:831-838.

Morikawa H, Khodakhah K, Williams JT (2003) Two intracellular pathways mediate metabotropic glutamate receptor-induced $\mathrm{Ca}^{2+}$ mobilization in dopamine neurons. J Neurosci 23:149-157.

Nedergaard S, Flatman JA, Engberg I (1993) Nifedipine- and omegaconotoxin-sensitive $\mathrm{Ca}^{2+}$ conductances in guinea-pig substantia nigra pars compacta neurones. J Physiol 466:727-747.

Neuhoff H, Neu A, Liss B, Roeper J (2002) $I_{\mathrm{h}}$ channels contribute to the different functional properties of identified dopaminergic subpopulations in the midbrain. J Neurosci 22:1290-1302.

Overton PG, Clark D (1997) Burst firing in midbrain dopaminergic neurons. Brain Res Brain Res Rev 25:312-334.

Ping HX, Shepard PD (1999) Blockade of SK-type $\mathrm{Ca}^{2+}$-activated $\mathrm{K}^{+}$ channels uncovers a $\mathrm{Ca}^{2+}$-dependent slow afterdepolarization in nigral dopamine neurons. J Neurophysiol 81:977-984.

Preston RJ, McCrea RA, Chang HT, Kitai ST (1981) Anatomy and physiology of substantia nigra and retrorubral neurons studied by extra- and intracellular recording and by horseradish peroxidase labeling. Neuroscience 6:331-344.

Pucak ML, Grace AA (1994) Evidence that systemically administered dopamine antagonists activate dopamine neuron firing primarily by blockade of somatodendritic autoreceptors. J Pharmacol Exp Ther 271:1181-1192.

Puopolo M, Raviola E, Bean BP (2007) Roles of subthreshold calcium current and sodium current in spontaneous firing of mouse midbrain dopamine neurons. J Neurosci 27:645-656.

Reynolds JN, Hyland BI, Wickens JR (2001) A cellular mechanism of reward-related learning. Nature 413:67-70.

Richards CD, Shiroyama T, Kitai ST (1997) Electrophysiological and immunocytochemical characterization of GABA and dopamine neurons in the substantia nigra of the rat. Neuroscience 80:545-557.

Schultz W (2006) Behavioral theories and the neurophysiology of reward. Annual Rev Psychol 57:87-115.

Schultz W, Dayan P, Montague PR (1997) A neural substrate of prediction and reward. Science 275:1593-1599.

Shen W, Flajolet M, Greengard P, Surmeier DJ (2008) Dichotomous dopaminergic control of striatal synaptic plasticity. Science 321:848-851.

Shepard PD, Bunney BS (1988) Effects of apamin on the discharge properties of putative dopamine-containing neurons in vitro. Brain Res 463:380-384.

Shepard PD, Stump D (1999) Nifedipine blocks apamin-induced bursting activity in nigral dopamine-containing neurons. Brain Res 817:104-109.

Stuart G, Schiller J, Sakmann B (1997) Action potential initiation and propagation in rat neocortical pyramidal neurons. J Physiol 505:617-632.

Tepper JM, Sawyer SF, Groves PM (1987) Electrophysiologically identified nigral dopaminergic neurons intracellularly labeled with HRP: lightmicroscopic analysis. J Neurosci 7:2794-2806.

Vetter P, Roth A, Häusser M (2001) Propagation of action potentials in dendrites depends on dendritic morphology. J Neurophysiol 85:926-937.

Wilson CJ, Callaway JC (2000) Coupled oscillator model of the dopaminergic neuron of the substantia nigra. J Neurophysiol 83:3084-3100.

Wilson CJ, Young SJ, Groves PM (1977) Statistical properties of neuronal spike trains in the substantia nigra: cell types and their interactions. Brain Res 136:243-260.

Yung WH, Häusser MA, Jack JJ (1991) Electrophysiology of dopaminergic and non-dopaminergic neurones of the guinea-pig substantia nigra pars compacta in vitro. J Physiol 436:643-667. 